\title{
Angiotensin-Il-derived reactive oxygen species on baroreflex sensitivity during hypertension: new perspectives
}

\author{
Thyago M. de Queiroz, Matheus M. O. Monteiro and Valdir A. Braga*
}

Department of Biotechnology, Biotechnology Center, Federal University of Paraiba, João Pessoa, Brazil

\section{Edited by:}

Ruy R. Campos, Federal University

of Sao Paulo, Brazil

Reviewed by:

Feng Chen, Georgia Health Sciences

University, USA

Marcos Lopez, Fundación

Cardiovascular de Colombia,

Colombia

\section{*Correspondence:}

Valdir A. Braga, Department of

Biotechnology, Biotechnology

Center, Federal University of

Paraiba, PO Box 5009, 58.051-970

João Pessoa, Brazil.

e-mail:valdir@cbiotec.ufpb.br
Hypertension is a multifactorial disorder, which has been associated with the reduction in baroreflex sensitivity (BRS) and autonomic dysfunction. Several studies have revealed that increased reactive oxygen species (ROS) generated by nicotinamide adenine dinucleotide phosphate $[N A D(P) H]$ oxidase, following activation of type 1 receptor $\left(A T_{1} R\right)$ by Angiotensin-(Ang) II, the main peptide of the Renin-Angiotensin-Aldosterone System (RAAS), is the central mechanism involved in Ang-II-derived hypertension. In the present review, we will discuss the role of Ang $I$ and oxidative stress in hypertension, the relationship between the BRS and the genesis of hypertension and how the oxidative stress triggers baroreflex dysfunction in several models of hypertension. Finally, we will describe some novel therapeutic drugs for improving the BRS during hypertension.

Keywords: hypertension, antioxidants, angiotensin-II, NADPH oxidase, baroreflex

\section{ANGIOTENSIN-II IS INVOLVED IN HYPERTENSION}

Angiotensin-(Ang) II is the key peptide of the Renin-Angiotensin-Aldosterone System (RAAS). This system consists mainly of an enzymatic cascade catalyzed by renin and angiotensin converting enzyme (ACE), generating Ang II (Peach, 1977; Griendling et al., 1993). The effect of Ang II is mediated by Ang II receptors. Two isoforms of the Ang II receptor have been identified: type 1 receptor $\left(\mathrm{AT}_{1} \mathrm{R}\right)$ and type 2 receptor $\left(\mathrm{AT}_{2} \mathrm{R}\right)$.

Ang II and its receptors have multiple systemic and local actions in different tissues, including blood vessels, kidneys, adrenal glands, heart and central nervous system (CNS) (Sadjadi et al., 2002; Campos, 2009; Campos et al., 2011). For instance, in the vasculature, activation of $\mathrm{AT}_{1} \mathrm{R}$ induces potent vasoconstriction (Ito et al., 1995; Oliverio et al., 1997). In the adrenal glands, their activation stimulates the release of aldosterone that in turn promotes sodium reabsorption in the mineralocorticoidresponsive segments of the distal nephron (Masilamani et al., 1999). In the kidneys, activation of $\mathrm{AT}_{1} \mathrm{R}$ is associated with renal vasoconstriction and antinatriuresis (Navar et al., 1987). Furthermore, $\mathrm{AT}_{1} \mathrm{R}$ is involved in the progression of cardiovascular diseases including hypertension, atherosclerosis, cardiac hypertrophy, and heart failure (Stegbauer and Coffman, 2011; Ichiki et al., 2012).

Additionally, expression of the $\mathrm{AT}_{2} \mathrm{R}$ increases under pathological situations ( $\mathrm{Li}$ et al., 2005; Padia and Carey, 2013). Therefore, activation of $\mathrm{AT}_{2} \mathrm{R}$ triggers nitric oxide (NO) release (Herrera and Garvin, 2010) and inhibits NF- $\kappa B$ and JAK/STAT signaling pathways. Thus, $\mathrm{AT}_{2} \mathrm{R}$ effects would potentially neutralize those of $\mathrm{AT}_{1} \mathrm{R}$ leading to cardiovascular protection. Moreover, $\mathrm{AT}_{2} \mathrm{R}$ activation directly antagonizes $\mathrm{AT}_{1} \mathrm{R}$ mediated actions (Horiuchi et al., 1999; Stegbauer and Coffman, 2011).

Regarding Ang II effects on the CNS, a high density of Ang II type 1 receptors was found in specific regions of the forebrain and in the rostral ventrolateral medulla (RVLM) (Allen et al., 1998). Of note, microinjection of Ang II into the RVLM produces an $\mathrm{AT}_{1} \mathrm{R}$-mediated increase in autonomous nervous system, resulting in increases in blood pressure (Dampney et al., 2007). Furthermore, the overexpression of $\mathrm{AT}_{1} \mathrm{R}$ in the RVLM increases blood pressure (Allen et al., 2006), and the blockade of $\mathrm{AT}_{1} \mathrm{R}$ in the RVLM has been associated to reduction blood pressure in several forms of experimental hypertension (Ito et al., 2002; Braga, 2010). Recently, using combined in vivo and molecular biology approaches, we have documented that Ang II-induced hypertension is mediated by an increase in sympathetic nerve activity, which seems to involve up-regulation of AT1 receptors in the RVLM and down-regulation of AT1 receptors in the subfornical organ (SFO) (Braga, 2011; Nunes and Braga, 2011).

An additional component of the RAAS family, angiotensin converting enzyme 2 (ACE2) cleaves Ang I and Ang II into Ang-(1-9) and Ang-(1-7), respectively (Chang et al., 2011). Ang(1-7) has opposite properties to that of Ang II. By acting through the Mas receptor, Ang-(1-7) promotes vasodilation, antiproliferation, and antihypertrophy (Santos et al., 2003; Ferrario et al., 2005). In the brain, Ang-(1-7) was reported to produce depressor responses when administered in the nucleus of the tractus solitarius (NTS) and dorsal motor nucleus of the vagus nerve (Campagnole-Santos et al., 1989). There is compelling evidence that ACE2 may play a pivotal role in counterbalancing the undesirable actions of the ACE/Ang II/AT ${ }_{1} \mathrm{R}$ axis and may be beneficial for the cardiovascular system (Xu et al., 2011). 


\section{OXIDATIVE STRESS IN HYPERTENSION}

The role of oxidative stress in the generation and/or maintenance of arterial hypertension has recently been reported in various animal models of hypertension, including the renovascular two-kidney-one-clip model (2K1C) (Oliveira-Sales et al., 2008; Botelho-Ono et al., 2011; Burmeister et al., 2011), the one-kidney-one-clip hypertension model (1K1C) (Prewitt et al., 2001), the Ang II-induced hypertension model (Zimmerman et al., 2002, 2004a; Laplante et al., 2003; Braga, 2011; Nunes and Braga, 2011), the Dahl salt-sensitive (DOCA-salt) hypertension model (Wu and De Champlain, 1999; Braga, 2010) the spontaneously hypertensive rat model (SHR) (Nishikawa et al., 2003; de Champlain et al., 2004; Guimarães et al., 2012; Monteiro et al., 2012) and the stroke-prone SHR model (SHRSP) (Chen et al., 2001; Kishi et al., 2004) as well as in humans (Duffy et al., 1999; Higashi et al., 2002; Campos et al., 2011).

For example, increased reactive oxygen species (ROS), including superoxide anion formation precedes the development of hypertension in SHR and in Ang II-infused mice (Kitiyakara and Wilcox, 1998; Houston, 2005; Braga et al., 2008; Botelho-Ono et al., 2011).

More than a decade ago, Griendling et al. (1994) first discovered that Ang II activates the vascular smooth muscle nicotinamide adenine dinucleotide phosphate $[\mathrm{NAD}(\mathrm{P}) \mathrm{H}]$ oxidase, an important cellular source of ROS (Griendling et al., 1994). Subsequently, it was shown that hypertension caused by Ang II infusion, but not norepinephrine infusion, increased vascular superoxide production in vivo (Rajagopalan et al., 1996) and that adenovirus-mediated superoxide dismutase (SOD) overexpression was effective in preventing this form of hypertension (Laursen et al., 1997; Zimmerman et al., 2004b; Davisson and Zimmerman, 2010; Lob et al., 2010).

The $\mathrm{NAD}(\mathrm{P}) \mathrm{H}$ oxidase is a multi-subunit enzyme and is one of the enzymatic sources of superoxide production. The NAD $(\mathrm{P}) \mathrm{H}$ oxidase has five subunits: p47phox ("phox" stands for phagocyte oxidase), p67phox, p40phox, p22 phox, and the catalytic subunit gp91phox (also termed "Nox2") (Chabrashvili et al., 2002; Babior, 2004). In unstimulated cells, p47phox, p67phox, and p40phox are located in the cytosol, whereas p22phox and gp91phox are in the membrane (Touyz et al., 2003). Upon stimulation, p47phox becomes phosphorylated and the cytosolic subunits form a complex that translocates to the membrane and activates the NAD(P)H oxidase complex (Touyz et al., 2003; Campos et al., 2011).

To fully understand how NADPH oxidase is involved in the context of neurogenic hypertension, and to be able to target it precisely, either experimentally or therapeutically, information about the expression patterns of the Nox homologues is required. To this end, Infanger et al. (2006) compared the expression levels of Nox1, Nox2, and Nox4 in different regions of mouse brain using real-time PCR. Their data showed that Nox2 as well as Nox4 are the predominant homologues expressed in fore-, mid-, and hind-brain of mice, while Nox1 is detectable but at very low levels. One limitation is that, in a variety of cell types, Nox transcript levels at baseline do not necessarily predict stimulus-induced activation of the enzymes, and opposing functions of various enzymes have been detected under different physiological conditions. Taken together, it is possible to suggest that an increase in NADPH oxidase-derived ROS in circumventricular organs CVOs, hypothalamic nuclei, and brainstem sites play a central role in the neurocardiovascular dysfunction observed in hypertension (Braga et al., 2011a,b).

Accumulating evidence now points to oxidative stress as a key mechanism in Ang II-dependent neurogenic hypertension (Kitiyakara and Wilcox, 1998; Houston, 2005; Burmeister et al., 2011). Inhibition of the $\mathrm{NAD}(\mathrm{P}) \mathrm{H}$ oxidase, with a decreased in oxidative stress, in CVOs of brain such as the SFO attenuated the cardiovascular and dipsogenic effects to intracerebroventricular (ICV) administration of Ang II (Zimmerman et al., 2004a; Peterson et al., 2009). Similar effect was observed in paraventricular nucleus of the hypothalamus (PVN) (Burmeister et al., 2011) and RVLM (Braga et al., 2008; Braga, 2010). More recently, Chrissobolis et al. (2012) have documented that Nox2 appears to be the more prominent mediator of the harmful effects of Ang II in the cerebral circulation during hypertension. In addition, injections of adenoviral vectors expressing small interfering (si)RNA targeting NOX2 (AdsiRNA-NOX2) or NOX4 (AdsiRNA-NOX4) mRNAs, used to knock down NOX2 and NOX4 proteins, in the PVN showed that either AdsiRNANOX2 or AdsiRNA-NOX4 significantly attenuated the development of Aldo/ $\mathrm{NaCl}$-induced hypertension (Xue et al., 2012). In an additional study by the same group, Aldo/salt-induced hypertension was also significantly attenuated in NOX2 (genomic) knockout mice compared with wild-type controls. When animals from both functional studies underwent ganglionic blockade, there was a reduced fall in blood pressure in the NOX2 and NOX4 knockdown/knockout mice, indicating that both NOX2 and NOX4 in the PVN contribute to hypertension (Xue et al., 2012).

In addition to ROS, reactive nitrogen species play an important role in the pathogenesis of hypertension. NO and peroxinitrite, their main players, have been reviewed elsewhere (Pacher et al., 2007). Briefly, the formation of reactive nitrogen species is a consequence of $\mathrm{NO}$ synthesis. Accumulating evidence suggests that alterations in NO synthesis and NO-sGC-cGMP signaling or a reduction in the bioavailability of endothelium-derived NO by increased oxidative stress are key contributors to the pathogenesis of hypertension (Wolin, 2005; Paravicini and Touyz, 2006). Increased levels of superoxide have been shown to decrease the bioavailability of NO, thereby contributing to the maintenance of elevated peripheral resistance (Cai and Harrison, 2000; Ungvari et al., 2004). NO is efficiently removed by reacting with oxyhemoglobin to form nitrate, which prevents even the highest rates of NO synthesis from directly reacting with oxygen to form significant amounts of nitrogen dioxide. However, the simultaneous activation of superoxide synthesis along with $\mathrm{NO}$ will transform the biological actions of NO by forming peroxynitrite (Pacher et al., 2007). Several enzyme complexes, including NADPH oxidases and xanthine oxidase, can be activated in many cellular systems to actively produce significant amounts of superoxide. When superoxide and NO are produced simultaneously in close proximity, modestly increasing superoxide and NO each at a 10fold will increase peroxynitrite formation by 100 -fold. Without superoxide, the formation of nitrogen dioxide by the reaction of 
NO with oxygen is miniscule by comparison (Pacher et al., 2007). $\mathrm{NO}$ and superoxide do not even have to be produced within the same cell to form peroxynitrite, because NO can so readily move through membranes and between cells. Although peroxynitrite is a strong oxidant, it reacts at a relatively slow rate with most biological molecules. Compelling evidence has emerged supporting the importance of endogenous peroxynitrite formation and protein nitration in the pathogenesis of arterial hypertension [reviewed in details by Turko and Murad (2002)].

\section{BAROREFLEX AND ANTIOXIDANTS}

The arterial baroreflex, regulated by the CNS acts to oppose the increase in blood pressure by inhibiting sympathetic activity, causing vasodilation and reducing heart rate (HR) in the short term. Previous reports have suggested that baroreflex sensitivity (BRS) is reduced during hypertension and the mechanisms underlying its reduction involves ROS (Braga, 2010; Botelho-Ono et al., 2011; Guimarães et al., 2012; Queiroz et al., 2012).

In recent decades, several research groups have worked extensively to improve the treatment of hypertension and its complication, including reduction in BRS, focusing on the discovery of new therapy strategies and drugs (Lefkowits and Willerson, 2001; Queiroz et al., 2011). Among these, we can highlight the use of antioxidant therapy, such as ROS scavengers and vitamins, SOD mimetics or $\mathrm{NAD}(\mathrm{P}) \mathrm{H}$ oxidase inhibitors that has experimentally shown to attenuate or prevent the development of hypertension (Chen et al., 2001; Landmesser et al., 2003; Costa et al., 2009; Queiroz et al., 2012).

It has been reported that microinjection of tempol into the RVLM decreased mean arterial pressure (MAP) and HR in SHRSP but not in WKY (Kishi and Hirooka, 2013). Other study demonstrated that acute intravenous infusion of ascorbic acid (Vitamin C) restores the reduced BRS in renovascular hypertension and that the inhibition of the $\mathrm{NAD}(\mathrm{P}) \mathrm{H}$ oxidase also restores BRS in hypertensive animals (Botelho-Ono et al., 2011). Moreover, it has been recognized that chronic administration of vitamin $\mathrm{C}$ for seven days improves BRS in renovascular hypertensive rats (Nishi et al., 2010).

Studies performing ICV injections of adenovirus encoding SOD (AdCuZnSOD) in SFO or RVLM demonstrated that the pressor effects caused by Ang II infusion were attenuated. Girouard et al. (2004) found that NAC or melatonin treatment in drinking water increased baroreflex control in response to pressor and depressor stimulations in SHR. In addition, the treatment enhanced increase basal plasma norepinephrine levels in hypertensive. Guimarães et al. (2012) showed that both

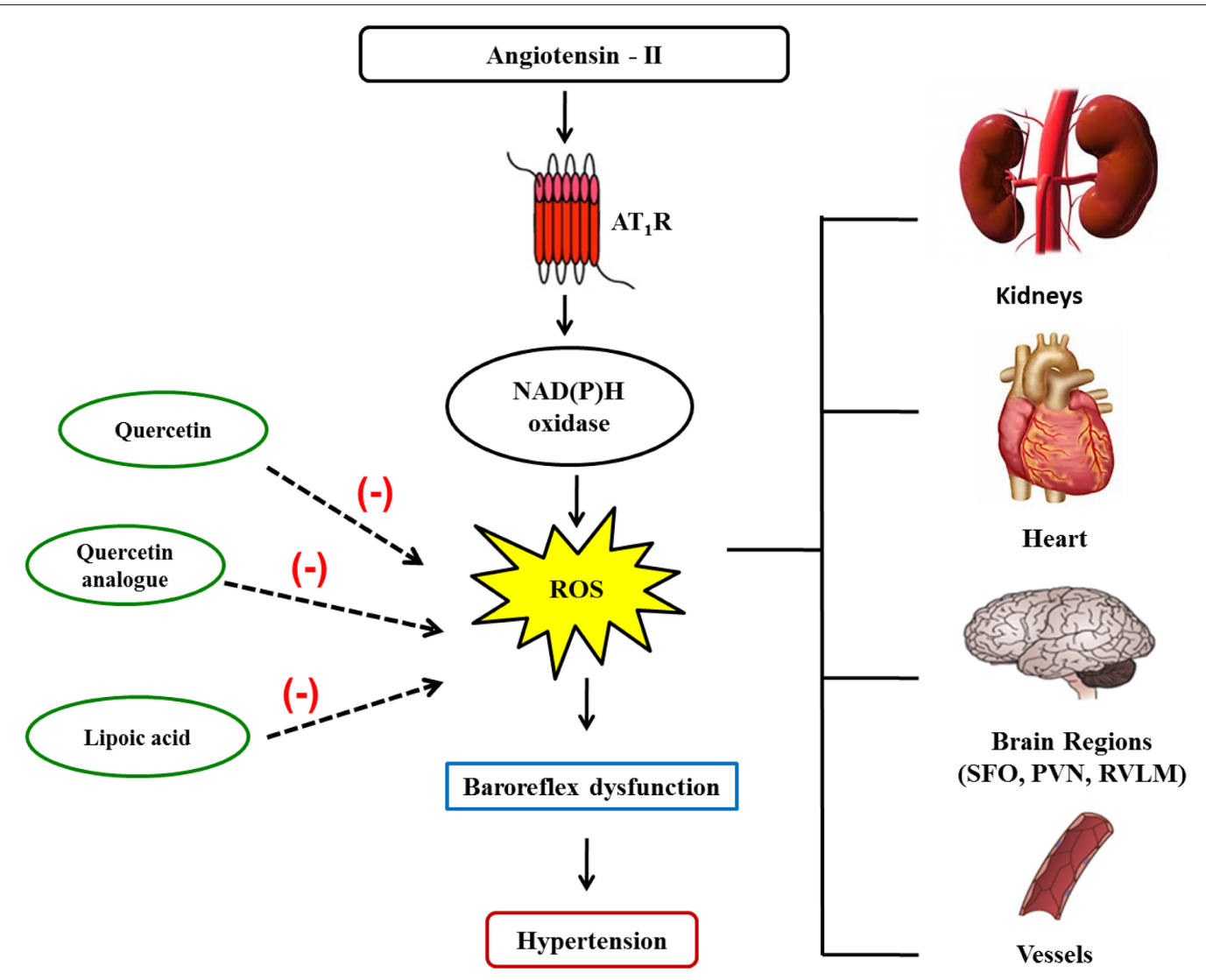

FIGURE 1 | Angiotensin II and its mechanisms to reduce baroreflex sensitivity. Angiotensin $\|$ binds to its receptors activating NADPH oxidase, which in turn increases reactive oxygen species (ROS) generation in several tissues. Within the brain, ROS leads to a reduction in the baroreflex sensitivity, which contributes to hypertension. Natural products such as quercetin, quercetin analogs, and alpha-lipoic acid, due to their antioxidant capability, improve baroreflex function, and ameliorate hypertension. 
acute intravenous administration of tiron, a SOD mimetic, and apocynin, a $\mathrm{NAD}(\mathrm{P}) \mathrm{H}$ oxidase inhibitor, induce reductions in oxidative stress triggering improvement in BRS in SHR.

Studies aiming to characterize the signal transduction mechanism of PI3-kinase involvement in Ang II-induced stimulation of central neuronal activity in cultured neurons and Ang IIinduced inhibition of baroreflex in SHR vs. WKY rats showed that application of Ang II to neurons produced a $42 \%$ greater increase in neuronal firing in cells from the SHR compared to WKY. Interestingly, the Ang II-mediated increase in firing rate was abolished entirely by the PKC inhibitor GF109230 in the WKY while it was necessary to block both PKC and PI3K activity to produce the same effect in the SHR (Sun et al., 2009). This was associated with an increased ability of Ang II to stimulate NADPH-oxidase-ROS mediated signaling involving phosphorylation of the p47phox subunit of the NADPH oxidase and was dependent on the activation of PI3 Kinase in the SHR. In addition, inhibition of PI3 Kinase resulted in the reduction of levels of p47phox phosphorylation, NADPH oxidase activity, ROS levels and ultimately neuronal activity in cells from the SHR but not the WKY rat. In addition, in working heart-brainstem preparations, inhibition of PKC activity in the NTS in situ abolished the Ang II-mediated depression of cardiac and sympathetic baroreceptor reflex gain in the WKY. In contrast, PKC inhibition in the NTS of SHR only partially reduced the effect of Ang II on the baroreceptor reflex gain (Sun et al., 2009).

Furthermore, aiming to determine whether or not chronic reduction of ROS in the RVLM improves impaired BRS in hypertensive rats, Ogawa et al. (2012) transfected adenovirus vectors encoding either manganese superoxide dismutase (AdMnSOD) or $\beta$-galactosidase (AdLacZ) into the RVLM of SHRSP and measured BRS using the spontaneous sequence method. They reported that BRS was significantly lower in SHRSPs than in WKY

\section{REFERENCES}

Allen, A. M., Dosanjh, J. K., Erac, M., Dassanayake, S., Hannan, R. D., and Thomas, W. G. (2006). Expression of constitutively active angiotensin receptors in the rostral ventrolateral medulla increases blood pressure. Hypertension 47, 1054-1061.

Allen, A. M., Moeller, I., Jenkins, T. A., Zhuo, J., Aldred, G. P., Chai, S. Y., et al. (1998). Angiotensin receptors in the nervous system. Brain Res. Bull. 47, 17-28.

Babior, B. M. (2004). NADPH oxidase. Curr. Opin. Immunol. 16, 42-47.

Botelho-Ono, M. S., Pina, H. V., Sousa, K. H. F., Nunes, F. C., Medeiros, I. A., and Braga, V. A. (2011). Acute superoxide scavenging restores depressed baroreflex sensitivity in renovascular hypertensive rats. Auton. Neurosci. 159, 38-44.

Braga, V. A. (2010). Dietary salt enhances angiotensin-II-induced superoxide formation in the rostral ventrolateral medulla. Auton. Neurosci. 155, 14-18.

Braga, V. A. (2011). Differential brain angiotensin-II type I receptor expression in hypertensive rats. J. Vet. Sci. 12, 291-293.

Braga, V. A., Burmeister, M. A., Zhou, Y., Sharma, R. V., and Davisson, R. L. (2008). Selective ablation of ATla receptors in rostral ventrolateral medulla (RVLM) prevents chronic angiotensin-II-dependent hypertension in part by reducing oxidant stress in this region. Hypertension 52,36 .

Braga, V. A., Colombari, E., and Jovita, M. G. (2011a). Angiotensin II-derived reactive oxygen species underpinning the pro-cessing of the cardiovascular reflexes in the medulla oblongata. Neurosci. Bull. 27, 269-274.

Braga, V. A., Medeiros, I. A., Ribeiro, T. P., França-Silva, M. S., BotelhoOno, M. S., and Guimarães, D. D. (2011b). Angiotensin-II-derived reactive oxygen species along the

rats. In addition, in AdMnSOD-transfected SHRSP, blood pressure, HR, and sympathetic nervous system activation were significantly decreased from day 5 after the gene transfer. In contrast, BRS in the AdMnSOD-transfected SHRSP was significantly increased from day 4 after the gene transfer with the reduction of ROS in the RVLM. Furthermore, in the AdMnSOD-transfected SHRSP, intravenous infusion of atropine dramatically decreased BRS. In contrast, in the AdLacZ-transfected SHRSP, atropine did not decrease BRS. Their results suggest that chronic reduction of ROS in the RVLM improves the impaired BRS in SHRSP through inhibition of the sympathetic component (Ogawa et al., 2012).

\section{PERSPECTIVES ON NATURAL PRODUCTS}

Studies from our laboratory revealed that natural products were capable of improving BRS through ROS scavenging mechanisms. The flavonoid quercetin improves both sympathetic and parasympathetic components of baroreflex and reduces MAP in SHR due to reduction of systemic oxidative stress. The mechanism is unknown, but it was suggested that this antioxidant can interfere with three or more different free radical-producing systems (Monteiro et al., 2012). Other study from our group showed that antioxidant therapy by chronic treatment with $\alpha$-lipoic acid, an endogenous antioxidant, reduces hypertension and improves BRS in rats with renovascular hypertension (Queiroz et al., 2012). Preliminary studies with a quercetin analog, rutin, demonstrated that this compound improved cardiovascular parameters altered during hypertension such as BRS and vascular reactivity, probably by a reduction in oxidative stress (Figure 1).

In conclusion, natural products with antioxidant properties have emerged as new potential therapeutic tools for improving BRS during hypertension. Although promising, there is still a long way until their use in the clinics becomes reality.

SFO-PVN-RVLM pathway: implications in neurogenic hypertension. Braz. J. Med. Biol. Res. 44, 814-965.

Burmeister, M. A., Young, C. N., Braga, V. A., Butler, S. D., Sharma, R. V., and Davisson, R. L. (2011). In vivo bioluminescence imaging reveal redox-regulated activator protein1 activation in paraventricular nucleus of mice with renovascular hypertension. Hypertension 57, 289-297.

Cai, H., and Harrison, D. G. (2000) Endothelial dysfunction in cardiovascular diseases: the role of oxidant stress. Circ. Res. 87, 840-844.

Campagnole-Santos, M. J., Diz, D. I., Santos, R. A., Khosla, M. C., Brosnihan, K. B., and Ferrario, C. M. (1989). Cardiovascular effects of angiotensin-(1-7) injected into the dorsal medulla of rats. Am. J. Physiol. Heart. Circ. Physiol. 257, 324-329.

Campos, R. R. (2009). Oxidative stress in the brain and arterial hypertension. Hypertens. Res. 32, 1047-1048.
Campos, R. R., Oliveira-Sales, E. B., Nish, E. M., Boim, M. A., Dolnikoff, M. S., and Bergamaschi, C. S. (2011). The role of oxidative stress in renovascular hypertension special series: stress and hypertension. Clin. Exp. Pharmacol. Physiol. 38, 144-152.

Chabrashvili, T., Tojo, A., Onozato, M. L., Kitiyakara, C., Quinn, M. T., Fujita, T., et al. (2002). Expression and cellular localization of classic $\mathrm{NADPH}$ oxidase subunits in the spontaneously hypertensive rat kidney. Hypertension 39, 269-274.

Chang, S. Y., Chen, Y. W., Chenier, I., Tran Sle, M., and Zhang, S. L. (2011). Angiotensin II type II receptor deficiency accelerates the development of nephropathy in type I diabetes via oxidative stress and ACE2. Exp. Diabetes Res. 2011:521076. doi: 10.1155/2011/ 521076

Chen, X., Touyz, R. M., Park, J. B., and Schiffrin, E. L. (2001). Antioxidant effects of vitamins C 
and $\mathrm{E}$ are associated with altered activation of vascular NADPH oxidase and superoxide dismutase in stroke-prone SHR. Hypertension 38, 606-611.

Costa, C. A., Amaral, T. A., Carvalho, L. C., Ognibene, D. T., da Silva, A. F., Moss, M. B., et al. (2009). Antioxidant treatment with tempol and apocynin prevents endothelial dysfunction and development of renovascular hypertension. Am. J. Hypertens. 22, 1242-1249.

Chrissobolis, S., Banfi, B., Sobey, C. G., and Faraci, F. M. (2012). Role of Nox isoforms in angiotensin II-induced oxidative stress and endothelial dysfunction in brain. $J$. Appl. Physiol. 113, 184-191.

Dampney, R. A., Tan, P. S., Sheriff, M. J., Fontes, M. A., and Horiuchi, J. (2007). Cardiovascular effects of angiotensin II in the rostral ventrolateral medulla: the push-pull hypothesis. Curr. Hypertens. Rep. 9, 222-227.

Davisson, R. L., and Zimmerman, M. C. (2010). Angiotensin, II, oxidant signaling, and hypertension: down to a T? Hypertension 55, 228-230.

de Champlain, J., Wu, R., Girouard, H., Karas, M., Midaoui, A. E., Laplante, M. A., et al. (2004). Oxidative stress in hypertension. Clin. Exp. Hypertens. 8, 593-601.

Duffy, S. J., Gokce, N., Holbrook, M., Huang, M., Frei, B., keaney, J. F., et al. (1999). Treatment of hypertension with ascorbic acid. Lancet 354, 2048-2049.

Ferrario, C. M., Trask, A. J., and Jessup, J. A. (2005). Advances in the biochemical and functional roles of angiotensin converting enzyme 2 and angiotensin- (1-7) in the regulation of cardiovascular function. Am. J. Physiol. Heart. Circ. Physiol. 289, 2281-2290.

Girouard, H., Denault, C., Chulak, C., and Champlain, J. (2004). Treatment by $\mathrm{N}$-acetylcysteine and melatonin increases cardiac baroreflex and improves antioxidant reserve. Am. J. Hypertens. 17, 947-954.

Griendling, K. K., Minieri, C. A., Ollerenshaw, J. D., and Alexander, R. W. (1994). Angiotensin II stimulates NADH and NADPH oxidase activity in cultured vascular smooth muscle cells. Circ. Res. 74, 1141-1148.

Griendling, K. K., Murphy, T. J., and Alexander, R. W. (1993). Molecular biology of the renin-angiotensin system. Circulation 87, 1816-1828.

Guimarães, D. D., Carvalho, C. C., and Braga, V. A. (2012).
Scavenging of NADPH oxidasederived superoxide anions improves depressed baroreflex sensitivity in spontaneously hypertensive rats. Clin. Exp. Pharmacol. Physiol. 39, 373-378.

Herrera, M., and Garvin, J. L. (2010). Angiotensin II stimulates thick ascending limb NO production via $\mathrm{AT}(2)$ receptors and Akt1dependent nitric-oxide synthase 3 (NOS3) activation. J. Biol. Chem. 285, 14932-14940.

Higashi, Y., Sasaki, S., Nakagawa, K., Matsuura, H., Oshima, T., and Chayama, K. (2002). Endothelial function and oxidative stress in renovascular hypertension. N. Engl. J. Med. 346, 1954-1962.

Horiuchi, M., Hayashida, W., Akishita, M., Tamura, K., Daviet, L., Lehtonen, J. Y. A., et al. (1999). Stimulation of different subtypes of angiotensin II receptors, $\mathrm{AT}_{1}$ and $\mathrm{AT}_{2}$ receptors, regulates STAT activation by negative crosstalk. Circ. Res. 84, 876-882.

Houston, M. C. (2005). Nutraceuticals, vitamins, antioxidants, and minerals in the prevention and treatment of hypertension. Prog. Cardiovasc. Dis. 47, 396-449.

Ichikawa, I., and Brenner, B. M. (1980). Importance of efferent arteriolar vascular tone in regulation of proximal tubule fluid reabsorption and glomerulotubular balance in the rat. J. Clin. Invest. 65, 1192-1201.

Ichiki, T., Miyazaki, R., Kamiharaguchi, A., Hashimoto, T., Matsuura, H., Kitamoto, S., et al. (2012). Resveratrol attenuates angiotensin II-induced senescence of vascular smooth muscle cells. Regul. Pept. 177, 35-39.

Infanger, D. W., Sharma, R. V., and Davisson, R. L. (2006). NADPH oxidases of the brain: distribution, regulation, and function. Antioxid. Redox Signal. 8, 1583-1596.

Ito, M., Oliverio, M. I., Mannon, P. J., Best, C. F., Maeda, N., Smithies, O., et al. (1995). Regulation of blood pressure by the type $1 \mathrm{~A}$ angiotensin II receptor gene. Proc. Natl. Acad. Sci. U.S.A. 92, 3521-3525.

Ito, S., Komatsu, K., Tsukamoto, K., Kanmatsuse, K., and Sved, A. F. (2002). Ventrolateral medulla $\mathrm{AT}_{1}$ receptors support blood pressure in hypertensive rats. Hypertension 40 , 552-559.

Kishi, T., and Hirooka, Y. (2013). Oxidative stress in the brain causes hypertension via sympathoexcitation. Front. Physiol. 3:335. doi: 10.3389/fphys.2012.00335

Kishi, T., Hirooka, Y., Kimura, Y., Ito, K., Shimokawa, H., and
Takeshita, A. (2004). Increased reactive oxygen species in rostral ventrolateral medulla contribute to neural mechanisms of hypertension in stroke-prone spontaneously hypertensive rats. Circulation 109, 2357-2362.

Kitiyakara, C., and Wilcox, C. S. (1998). Antioxidants for hypertension. Curr. Opin. Nephrol. Hypertens. 7, 531-538.

Landmesser, U., Dikalov, S., Price, S. R., Mc-Cann, L., Fukai, T., Holland, S. M., et al. (2003). Oxidation of tetrahydrobiopterin leads to uncoupling of endothelial cell nitric oxide synthase in hypertension. J. Clin. Investig. 111, 1201-1209.

Laplante, M. A., Wu, R., El Midaoui, A., and De Champlain, J. (2003). $\mathrm{NAD}(\mathrm{P}) \mathrm{H}$ oxidase activation by angiotensin II is dependent on $\mathrm{p} 42$ / 44 ERK-MAPK pathway activation in rats vascular smooth muscle cells. J. Hypertens. 21, 927-936.

Laursen, J. B., Rajagopalan, S., Galis, Z., Tarpey, M., Freeman, B. A., and Harrison, D. G. (1997). Role of superoxide in angiotensin II-induced but not catecholamine induced hypertension. Circulation 95, 588-593.

Lefkowits, R. J., and Willerson, J. (2001). Prospects for cardiovascular research. JAMA 285, 581-587.

Li, J., Culman, J., Hortnagl, H., Zhao, Y., Gerova, N., Timm, M., et al. (2005). Angiotensin $\mathrm{AT}_{2}$ receptor protects against cerebral ischemia induced neuronal injury. FASEB $J$. 19, 617-619.

Lob, H. E., Marvar, P. J., Guzik, T. J., Sharma, S., McCann, L. A., Weyand, C., et al. (2010). Induction of hypertension and peripheral inflammation by reduction of extracellular superoxide dismutase in the central nervous system. Hypertension 55, 277-283.

Masilamani, S., Kim, G. H., Mitchell, C., Wade, and J. B., Knepper, M. A. (1999). Aldosterone-mediated regulation of $\mathrm{ENaC} \alpha, \beta$, and $\gamma$ subunit proteins in rat kidney. J. Clin. Invest. 104, 19-23.

Monteiro, M. M. O., França-Silva, M. S., Alves, N. F. B., Porpino, S. K. P., and Braga, V. A. (2012). Quercetin improves baroreflex sensitivity in spontaneously hypertensive rats. Molecules 17, 12997-13008.

Navar, L. G., Carmines, P. K., Huang, W. C., and Mitchell, K. D. (1987). The tubular effects of angiotensin II. Kidney Int. Suppl. 20, 81-88.

Nishi, E. E., Oliveira-Sales, E. B., Bergamaschi, C. T., Oliveira, T. G., Boim, M. A., and Campos, R. R. (2010). Chronic antioxidant treatment improves arterial renovascular hypertension and oxidative stress markers in th e kidney in Wistar rats. Am. J. Hypertens. 23, 473-480.

Nishikawa, Y., Tatsumi, K., Matsura, T., Yamamoto, A., Nadamoto, T., and Urabe, K. (2003). Effects of vitamin $\mathrm{C}$ on high blood pressure induced by salt in spontaneously hypertensive rats. J. Nutr. Sci. Vitaminol. 49, 301-309.

Nunes, F. C., and Braga, V. A. (2011). Chronic angiotensin II infusion modulates angiotensin II type I receptor expression in the subfornical organ and the rostral ventrolateral medulla in hypertensive rats. J. Renin Angiotensin Aldosterone Syst. 12, 440-445.

Ogawa, K., Hirooka, Y., Shinohara, K., Kishi, T., and Sunagawa, K. (2012). Inhibition of oxidative stress in rostral ventrolateral medulla improves impaired baroreflex sensitivity in stroke-prone spontaneously hypertensive rats. Int. Heart. J. 53, 193-198.

Oliveira-Sales, E. B., Dugaich, A. P., and Abreu, N. P. (2008). Oxidative stress supports blood pressure and sympathetic activity in renovascular hypertension. Am. J. Hypertens. 21, 98-104.

Oliverio, M. I., Best, C. F., Kim, H. S., Arendshorst, W. J., Smithies, O., and Coffman, T. M. (1997). Angiotensin II responses in $\mathrm{AT}_{1} \mathrm{~A}$ receptordeficient mice: a role for $\mathrm{AT}_{1} \mathrm{~B}$ receptors in blood pressure regulation. Am. J. Physiol. 272, 515-520.

Pacher, P., Beckman, J. S., and Liaudet, L. (2007). Nitric oxide and peroxynitrite in health and disease. Physiol. Rev. 87, 315-424.

Padia, S. H., and Carey, R. M. (2013). AT2 receptors: beneficial counterregulatory role in cardiovascular and renal function. Pflugers Arch. 465, 99-110.

Paravicini, T. M., and Touyz, R M. (2006). Redox signaling in hypertension. Cardiovasc. Res. 71, 247-258.

Peach, M. J. (1977). Renin-angiotensin system: biochemistry and mechanisms of action. Physiol. Rev. 57, 313-370.

Peterson, J. R., Burmeister, M. A., Tian, X., Zhou, Y., Guruju, M. R., Stupinski, J. A., et al. (2009). Genetic silencing of Nox2 and Nox4 reveals differential roles of these NADPH oxidase homologues in the vasopressor and dipsogenic effects of brain angiotensin, II. Hypertension 54, 1106-1114.

Prewitt, R. L., Dobrian, A. D., and Schriver, S. D. (2001). Role of 
Angiotensin II and free radicals in blood pressure regulation in a rat model of renal hypertension. Hypertension 38, 361-366.

Queiroz, T. M., Guimarães, D. D., Mendes-Júnior, L. G., and Braga, V. A. (2012). $\alpha$-Lipoic acid reduces hypertension and increases baroreflex sensitivity in renovascular hypertensive rats. Molecules 17, 13357-13367.

Queiroz, T. M., MacHado, N. T., Furtado, F. F., Oliveira-Filho, A. A., Alustau, M. C., Figueiredo, C. S., et al. (2011). Vasorelaxation induced by Dictyota pulchella (Dictyotaceae), a brown alga, is mediated via inhibition of calcium influx in rats. Mar. Drugs 9, 2075-2088.

Rajagopalan, S., Kurz, S., Munzel, T., Tarpey, M., Freeman, B. A., Griendling, K. K., et al. (1996). Angiotensin II-mediated hypertension in the rat increases vascular superoxide production via membrane $\mathrm{NADH} / \mathrm{NAD}(\mathrm{P}) \mathrm{H}$ oxidase activation: contribution to alterations of vasomotor tone. J. Clin. Investig. 97, 1916-1923.

Sadjadi. J., Puttaparthi. K., Welborn, M. B., Rogers, T. E., Moe, O., Clagett, G. P., et al. (2002). Upregulation of autocrineparacrine reninangiotensin systems in chronic renovascular hypertension. J. Vasc. Surg. 36, 386-392.
Santos, R. A. S., Silva, A. C. S., Maric, C., Silva, D. M. R., MacHado, R. P., de Buhr, I., et al. (2003). Angiotensin-(1-7) is an endogenous ligand for the $\mathrm{G}$ protein coupled receptor Mas. Proc. Natl. Acad. Sci. U.S.A. 100, 8258-8263.

Stegbauer, J., and Coffman, T. M. (2011). New insights into angiotensin receptor actions: from blood pressure to aging. Curr. Opin. Nephrol. Hypertens. 20, 84-88.

Sun, C., Zubcevic, J., Polson, J. W., Potts, J. T., Diez-Freire, C., Zhang, Q., et al. (2009). Shift to an involvement of phosphatidylinositol 3kinase in angiotensin II actions on nucleus tractus solitarii neurons of the spontaneously hypertensive rat. Circ. Res. 105, 1248-1255.

Touyz, R. M., Yao, G., and Schiffrin, E. L. (2003). c-Src induces phosphorylation and 533translocation of p47phox: role in superoxide generation by angiotensin II in human 534 vascular smooth muscle cells. Arterioscler. Thromb. Vasc. Biol. 23, 981-987

Turko, I. V., and Murad, F. (2002). Protein nitration in cardiovascular diseases. Pharmacol. Rev. 54, 619-634.

Ungvari, Z., Csiszar, A., Kaminski, P. M., Wolin, M. S., and Koller, A. (2004). Chronic high pressureinduced arterial oxidative stress: involvement of protein kinase C-dependent $\mathrm{NAD}(\mathrm{P}) \mathrm{H}$ oxidase and local renin-angiotensin system. Am. J. Pathol. 165, 219-226.

Wolin, M. S. (2005). Loss of vascular regulation by soluble guanylate cyclase is emerging as a key target of the hypertensive disease process. Hypertension 45, 1068-1069.

Wu, L., and De Champlain, J. (1999). Effects of superoxide on signaling pathways in smooth muscle cells from rats. Hypertension 34, 1247-1253.

$\mathrm{Xu}, \mathrm{P} .$, Sriramula, S., and Lazartigues, E. (2011). ACE2/ANG-(1-7)/Mas pathway in the brain: the axis of good. Am. J. Physiol. Regul. Integr. Comp. Physiol. 300, 804-817.

Xue, B., Beltz, T. G., Johnson, R. F. Guo, F., Hay, M., and Johnson, A. K. (2012). PVN adenovirus-siRNA injections silencing either NOX2 or NOX4 attenuate aldosterone/ $\mathrm{NaCl}-$ induced hypertension in mice. Am. J. Physiol. Heart Circ. Physiol. 302, H733-H741.

Zimmerman, M. C., Dunlay, R. P., Lazartigues, E., Zhang, Y., Sharama, R. V., Engelhardt, J. F., et al. (2004a). Requirement for Rac 1-dependent NADPH oxidase in the cardiovascular and dipsogenic actions of angiotensin II in the brain. Circ. Res. 95, 532-539.

Zimmerman, M. C., Lazartigues, E. Sharma, R. V., and Davisson, R. L. (2004b). Hypertension caused by angiotensin II infusion involves increased superoxide production in the central nervous system. Circ. Res. 95, 210-216.

Zimmerman, M. C., Lazartigues, E., Lang, J. A., Sinnayah, P., Ahmad, I. M., Spitz, D. R., et al. (2002). Superoxide mediates the actions of angiotensin II in the central nervous system. Circ. Res. 91, 1038-1045.

Conflict of Interest Statement: The authors declare that the research was conducted in the absence of any commercial or financial relationships that could be construed as a potential conflict of interest.

Received: 28 February 2013; accepted: 24 April 2013; published online: 13 May 2013

Citation: de Queiroz TM, Monteiro MMO and Braga VA (2013) Angiotensin-II-derived reactive oxygen species on baroreflex sensitivity during hypertension: new perspectives. Front. Physiol. 4:105. doi: 10.3389/fphys 2013.00105

This article was submitted to Frontiers in Oxidant Physiology, a specialty of Frontiers in Physiology.

Copyright (C) 2013 de Queiroz, Monteiro and Braga. This is an open-access article distributed under the terms of the Creative Commons Attribution License, which permits use, distribution and reproduction in other forums, provided the original authors and source are credited and subject to any copyright notices concerning any third-party graphics etc. 